\title{
Evaluation of Rate of the Reduction in Road Capacity at Kerb side Bus Stop in Urban areas under Mixed Traffic conditions - a case study in Hyderabad city
}

\author{
Dr Raju Ramesh Reddy \\ Professor in Civil Engineering department, Arba Minch University, Arba Minch, Ethiopia
}

\begin{abstract}
Capacity of mid block, in general represents the maximum hourly rate at which vehicles reasonably can be expected to traverse a point or section of a lane during a given time period under prevailing roadway and traffic conditions. Roadway conditions refer to the type of facility, its geometric characteristics, the number of lanes, lateral clearances, design speed, horizontal and vertical alignments. Traffic conditions refer to the composition and distribution of traffic in available lanes. Improvements and changes in geometric features, junction features, traffic control devices and traffic management measures can be designed effectively by proper estimation of capacity. The adequacy or deficiency of a network can be assessed by comparing the present traffic volume with the capacity of existing network. The distribution of traffic in each lane can be planned by measuring its link capacity. The capacity of mid block is not only a function of available road width but varies based on the traffic volume and its composition and other impedances that act on traffic flow continuously. In a mixed urban traffic flow, when the flow rates approaches to capacity, the congestion takes place causing excessive delay to vehicles. In the present study, three kerb side bus stops in Hyderabad city of varying road widths and traffic characteristics are considered to evaluate the reduction in roadway capacity due to kerb side bus stop under variable roadway and traffic conditions. Whenever a bus, stops at a kerb side bus stop, the effective road width available for traffic movement reduces there by creating a bottleneck situation. The impedance caused by the activity of buses at a kerb side bus stop on the quality of traffic can also be assessed by comparing the capacities of the road not affected by the bus stop and the bottleneck or the capacity resulting due to reduced road width. An attempt is made in this study to understand the reduction of capacity at each of the selected bus stops. Using curve enveloping technique, capacity graphs are plotted based on speed - volume relationships for the sections of road, away from the bus stop and also at the bus stop. A comparison of these graphs indicates the reduction in capacity due to the kerb side bus stop. This reduced capacity is a key factor that influences the traffic dynamics at the bus stop and the complex relationships between the various parameters that are inherently affected by these capacity values.
\end{abstract}

\section{Introduction}

Traffic in most of the developing countries such as India is heterogeneous in nature, comprising different types of vehicles with wide ranging physical dimensions, weights and dynamic characteristics, moving on any available part of road space without any lane discipline. Under heterogeneous traffic conditions, different types of vehicles moving on the same road system may enjoy different levels of service. The most important parameter that reflects the nature of traffic flow in urban corridors is the speed of vehicles. The speed of vehicles in urban roads varies based on the traffic volume and its composition, available road width and other locational features, such as the presence of side lanes, on- street parking, kerb side bus stops, street vendors, pedestrian crossing, etc.

Hyderabad is the capital city and most populous city in the Indian state of Telangana. As per the statistical records, the city of Hyderabad has an estimated population of around 6.1 million. Greater Hyderabad metropolitan area has an estimated metropolitan population of 9.6 million, making it as an A-1 status city. The average decadal growth rate of population is estimated as around 32 percent. Studies have indicated that the population levels in Hyderabad city are likely to be anywhere between 12.24 million to 17.3 million by the end of 2021. Nearly 4,000 city buses are running across the city every day from 6:00 a.m. to 11:30 p.m covering all parts of the city.

Hyderabad has the highest density of vehicles per kilometer with 2,337 vehicles per kilometer of road space, with more than 10,000 new vehicles being added to the city roads every month, with approximately 600 new vehicles join the city roads every day, as per the statement given in the website of GHMC (www.ghmc.gov.in). As per statistics, only 44 per cent of Hyderabad population depends on public transportation, especially towards RTC buses. The total number of vehicles in the twin cities had crossed 22 lakh with autos numbering over 1.5 lakh, two wheelers 16.8 lakh and cars 1.67 lakh. It is estimated that in peak hours, most of the major corridors carry more than 9000 passenger car units. The city traffic in peak hours is 
subjected to a lot of congestion and delays with very low journey speed as low as $10 \mathrm{Kmph}$. Frequent weaving movements of buses and trucks in busy corridors have a significant effect on the speed of traffic. Further, stoppage of buses in the direction of traffic at the bus stops tends to block the traffic moving on the left lane. 252 bus bays have been identified in Hyderabad city for provision of convenient stoppages for buses without causing inconvenience to the through traffic. It is noticed that the patronage of buses has remained stable over the years, even though the population is increasing each year.

\section{Need for the present study :}

Under heterogeneous traffic conditions in Hyderabad city, most of the bus stops are located at the kerb side thus causing a reduction in available road width. This affects the speed of vehicles and increases the operational delay. Due to the lack of training and discipline, the bus drivers stop the buses haphazardly at the kerb side bus stop without utilizing the available road space effectively. Moreover the commuters at the kerb side bus stop in Hyderabad city are forced to occupy certain part of road especially in peak hours thus causing a lot of reduction in road width.

When the buses stop on the road at a kerb side bus stop, some of the road space is lost depending on the position where the bus is stopped, thus reducing the effective road width available for the other traffic. The reduction in the road space will obviously affect the capacity of the road and have an impact on speed of other vehicles creating a bottleneck situation. The quantification of rate of the reduction in road capacity due to kerb side bus stop for variable road way and traffic conditions by considering all the influencing parameters is essential for the planner to take some policy decisions in establishing the kerb side bus stop in urban areas. The present study is an attempt to fulfill this need.

\section{Objectives of the study :}

The study is aimed to evaluate the capacity of mid blocks and its reduction at each selected kerb side bus stop, in order to correlate the reduction in speed with the reduction in capacity. The broad objectives of the study are as follows :

To conduct various traffic studies such as traffic volume, speed and effective road widths at selected kerb side bus stop locations in Hyderabad city under various roadway and traffic conditions.

To evaluate the Capacity of road at and away from each selected bus stop and to observe the variation of impedance in terms of reduction in Capacity bus stop wise.

\section{Review of Literature}

The various researches carried out earlier in the fields related to the present study are reviewed and presented. More emphasis is placed on the research carried on speed-flow relationship, capacity and level of service, bus stop influence on flow characteristics. The urban traffic behavior under varied traffic flow conditions was analysed and a simulation model was developed by Dr. Satish Chandra and Dr. M. Parida (2004). It was concluded that the rate of decrease in speed with traffic volume is different for different types of vehicles. Further it is expressed that the effect is more for three wheelers and heavy vehicles than two wheelers. Similarly, a study was conducted by Rajat Bose et al., (2004) in Delhi to assess the effect of cycle rickshaws on traffic flow. The study was made in different lanes and observed that the impacts of cycle rickshaws are very significant on the speed of the traffic flow of the network as compared to the other factors.

Kay Fitzpatrick P.E, et al., (2005) conducted a study on exploration of the relationships between operating speed and roadway features on tangent sections. It was concluded that several features such as pedestrian activity, parking, centre line, median treatment, road side development, area type and signal density have influence on $85^{\text {th }}$ percentile free flow operating speed. Key Fitzpatrick, et al., (2006) conducted a study for predicting speed in urban right turn lanes in order to know the right turn impact on right turn vehicles. On the basis of Speed prediction equations, it was observed that the $85^{\text {th }}$ percentile free flow speed near the middle of the right turn was ranged from $20.9 \mathrm{~km} / \mathrm{hr}$ to $33.8 \mathrm{~km} / \mathrm{hr}$ while on the approach it was ranged from $27.4 \mathrm{~km} / \mathrm{hr}$ to $46.7 \mathrm{~km} / \mathrm{hr}$.

Satish Chandra (2004) conducted a study to establish a relationship between roughness of the road and capacity of two lane road. It was observed that the capacity decreases by $300 \mathrm{pcu} / \mathrm{hr}$ when surface unevenness increases by $1000 \mathrm{~mm} / \mathrm{km}$ and the capacity of a two lane road could be augmented by $10-15 \%$ by providing a good riding surface. Dr. V. Thamizh Arasan and Reebu Zachariah Koshy (2004) developed a simulation model for heterogeneous traffic flow to estimate capacity and service volume standards for urban roads. It was observed that the service volumes at Level of Service C for one way traffic flow on $7.5 \mathrm{~m}$ and $11.0 \mathrm{~m}$ wide road space are around 2250 and $3150 \mathrm{pcu} / \mathrm{hr}$ respectively, where as the Capacity values for the same road spaces with traffic in one direction were obtained as about 3200 and 4500 cars per hour by the simulation model and found to be higher than the capacity values recommended by IRC- 86 . 
David J. Victor and S. Moses Santhakumar (1986) developed a computer simulation model to evaluate the impact of various transportation system management measures on the performance of bus transit. It was observed from the model that the travel time of a bus along a route could be reduced by about $4 \%$, if the running speed could be increased by $5 \mathrm{kmph}$ using appropriate TSM measures. Razi A. Siddiqi (1986) developed a methodology to evaluate the service quality of bus lanes in urban areas. It was concluded that the lanes having lower values of service quality do not have unusual rush hour problem and needs improvement immediately either by increasing the number of buses or by increasing the number of seats.

Dr. Palanichamy M.S, et al., (1998) conducted a study on user perception for the shuttle bus transit system at Madurai. It was concluded that in order to increase the perception rate of commuters on bus shuttle transit system, the bus fare should be affordable and cheaper and the passenger amenities in bus terminals should also be improved. It was also expressed that widening of entrance and exit, proper provision for parking and cleaning of hawkers would reduce the excess time at entry and exit points. A study on the influence of kerb side bus stops on traffic flow under heterogeneous traffic conditions using a simulation technique was carried out by Reebu Zachariah Koshy and V. Thamizh Arasan (2005). It was concluded that a kerb side bus stop with $20 \mathrm{sec}$ average bus dwell time, causes an approximate $25 \%$ speed reduction to traffic at a flow level of about $2400 \mathrm{veh} / \mathrm{hr}$.

\section{Locations of Study for Data Collection :}

For the present study, three Kerb side bus stop locations having different traffic conditions and road widths ranging from $8 \mathrm{~m}$ to $13 \mathrm{~m}$, in Hyderabad are considered. All the study locations selected are in the mid blocks of major corridors in Hyderabad city with heavy traffic movements both in peak and non- peak hours. These mid blocks are divided roads and there is no pedestrian crossing and negligible on street parking at and nearby the bus stops selected for the study. Table 1 gives the details of the selected three kerb side bus stop locations.

Table 1. Details of selected kerb side Bus Stops

\begin{tabular}{|c|c|c|c|}
\hline Bus Stop No & Name of the Bus Stop & Mid-block Name & Road width (m) \\
\hline 1 & Bus Bhavan & R.T.C Cross Roads- Vidya nagar Junction & 9.4 \\
\hline 2 & L.I.C & Lumbini park Junction to Ravindra Bharati Junction & 12.2 \\
\hline 3 & Nalgonda X Roads & Nalgonda Cross Roads- Saidabad & 8.2 \\
\hline
\end{tabular}

\section{Data Collection and Survey Method}

In the present study, different traffic surveys are conducted at each selected kerb side bus stop location to collect the traffic data such as classified traffic volume, speed of vehicles at and away from the bus stop, approach road width and effective road width. The data is collected for 12 hours in a day at each bus stop, during peak and non peak hours with an interval of 15 minutes duration. The following methodology is adopted for the data collection at each selected bus stop location for different surveys. All the surveys at each location are carried out simultaneously so as to fulfill the objective of developing relationships between different parameters.

\section{Traffic volume studies:}

Classified traffic volume counts are carried out at the selected bus stop locations by manual method, at two different stations, in which Station 1 is taken at some distance away from the bus stop on the upstream side, where the vehicles are not affected by the presence of kerb side bus stop and Station 2 is taken exactly at the bus stop, where there is a definite impact on traffic flow due to its presence. The station 1 is selected after careful observation of traffic throughout the day and after ensuring that the stoppages of buses at the bus stop do not affect the speeds of vehicles at that station. Though there is an element of subjectivity because of the discretion and judgment, utmost care is taken to ensure the required criterion. For this reason, the distance between station 1 and station 2 is not uniform at all the study locations. The concept is shown inthe diagram and presented in Fig. 1.

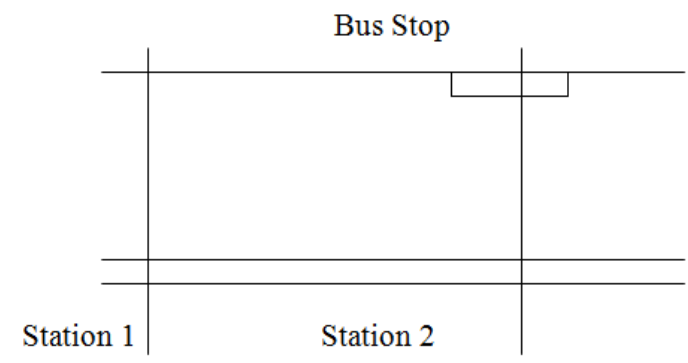

Fig. 1. Sections adopted for Volume Study at a typical Bus stop 
The traffic volume data collected is then converted into pcu/ hr by considering pcu factors as per IRC Code No : 106-1990 (Guide lines for Capacity of Urban Roads in Plain Areas).

\section{Traffic Speed Studies :}

The traffic speed is measured at each kerb side bus stop location in terms of Time mean speed by using direct timing procedure method. For this, two different sections are considered. Section 1 is taken at some distance away from the bus stop, in which the speeds of vehicles are not affected by the presence of kerb side bus stop as mentioned in earlier article. Section 2 is taken such that the bus stop falls within the section almost at the centre so that the effect of stopped buses on speeds can be captured. The times of entry and exit of different vehicles over the length of these sections are recorded and based on the trap length of $30 \mathrm{~m}$ fixed for each section, the time mean speeds are computed. The space mean speed is then calculated from the time mean speed by using the formula:

$$
\mathrm{S}=(3.6 \times \mathrm{d} \times \mathrm{n}) / \Sigma \mathrm{t},
$$

where

$$
\begin{aligned}
& \mathrm{S}=\text { Space Mean Speed }(\mathrm{SMS}) \\
& \mathrm{d}=\text { distance between two sections considered } \\
& \mathrm{n}=\text { number of samples taken } \\
& \Sigma \mathrm{t}=\text { sum of the time taken for the selected samples }
\end{aligned}
$$

Space Mean Speed (SMS) represents the average speed of vehicles measured at an instant of time over a given space, which is considered to be more appropriate for the analysis of the present study, as it gives the average speed of vehicles for the entire space considered in the $\mathrm{s}$ areaof study and not for a single point. Reduced speed is evaluated by taking the difference of the speed measured at both the sections. The schematic diagram showing the typical sections considered for speed studies at a bus stop is presented in Fig.2.

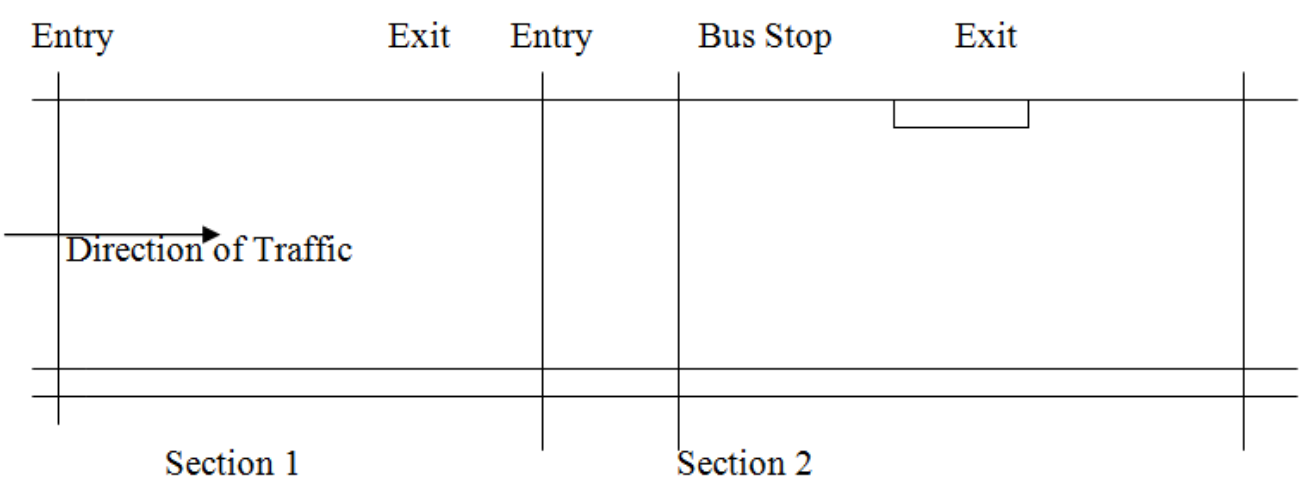

Fig. 2. Sections adopted for Speed data collection at a typical Bus stop

\section{Effective Road Width (ERW):}

In the present study, a parameter called Effective Road Width is used to indicate the available carriageway width for traffic in meters, whenever a bus, stops on the road at a kerb side bus stop. It is a common observation that all the buses do not stop at the same point and the position of the bus when it stops depends on many factors such as the driver's attitude and the amount of passenger traffic waiting by the kerb side. In order to capture this effective road width, it is important to note where the bus stops and how much road width is lost due to bus stoppage.

The methodology adopted for computing this effective road width is as follows: First of all, the clear carriageway width available at the bus stop is recorded when no bus is there at the bus stop. Longitudinal reference lines are marked on the road at $0.5 \mathrm{~m}$ intervals from the centre of carriageway towards bus stop upto $2.0 \mathrm{~m}$ from the kerb line. The reasonable assumption here is that in any case, the stopped bus will not occupy road space beyond half of the carriageway available, as minimum carriageway considered in the study is $8.2 \mathrm{~m}$. In each 15 minute interval, whenever a bus is stopped at the bus stop, the width lost due to it's stoppage is recorded by noting down the reference point occupied by the body of the bus. The concept is illustrated by Fig. 3 and Fig.4.

Fig. 3 shows a road where carriageway available for one direction traffic is $9.0 \mathrm{~m}$. So, reference lines are marked from $4.5 \mathrm{~m}$ from the kerb side upto $2.0 \mathrm{~m}$ towards kerb side. Fig. 4 presents a hypothetical case where a bus is stopped and based on its position with respect to reference lines, it can be seen that it occupies a road width of $3.5 \mathrm{~m}$. So, the effective road width available for the remaining traffic is $5.5 \mathrm{~m}$ as indicated in the figure. 
Kerb side bus stop

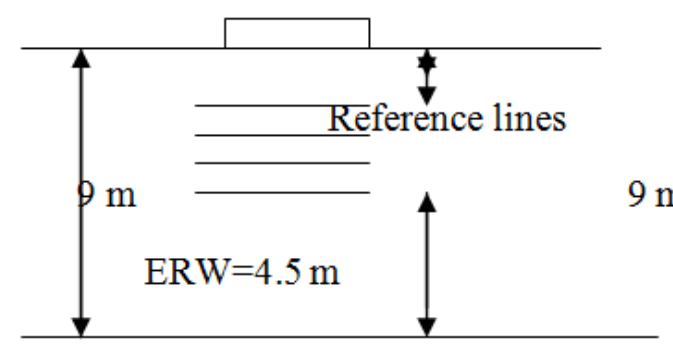

Kerb side bus stop

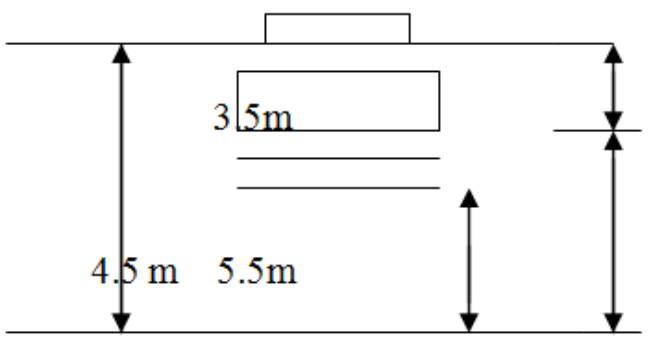

Fig. 3 \& Fig. 4 Sections adopted for Effective Road Width data collection

Thus for each bus stop, after the bus is stopped during a given 15 minute interval, the effective road width is calculated.

\section{Road Width (RW):}

The width of approach road is measured as the carriageway width at each kerb side bus stop and is recorded in terms of meters. The road width refers to the width available from the edge of the divider to the kerb of the road.

\section{Development of Capacity curves and Evaluation of Capacity Reduction:}

In order to understand the variation of capacity at each kerb side bus stop and to evaluate the reduction in capacity location wise, capacity curves are plotted at all the kerb side bus stops at the sections before the bus stop and at the bus stop and are presented through Fig. 5 to Fig. 10. In order to plot the capacity curves at and away from each kerb side bus stop, the corresponding volume and speed data is considered. The capacity curves are then plotted by adopting curve enveloping technique. The approach capacity and capacity at bus stop is then evaluated from these curves at each section by measuring the volume corresponding to half of the free flow speed. The capacity curves plotted at Bus Bhavan bus stop are presented through Fig. 5 and Fig. 6. The approach capacity and Capacity values at bus stop at this section are found to be lower as compared to Urvasi Restaurent bus stop and are $5800 \mathrm{pcu} / \mathrm{hr}$ and $4300 \mathrm{pcu} / \mathrm{hr}$ with a higher reduction in capacity of $1500 \mathrm{pcu} / \mathrm{hr}$.

The capacity curves plotted at LIC bus stop are presented through Fig. 7 and Fig. 8. The approach capacity and capacity values at bus stop at this location are found to be $6750 \mathrm{pcu} / \mathrm{hr}$ and $5550 \mathrm{pcu} / \mathrm{hr}$ with a reduction in capacity of $1200 \mathrm{pcu} / \mathrm{hr}$.

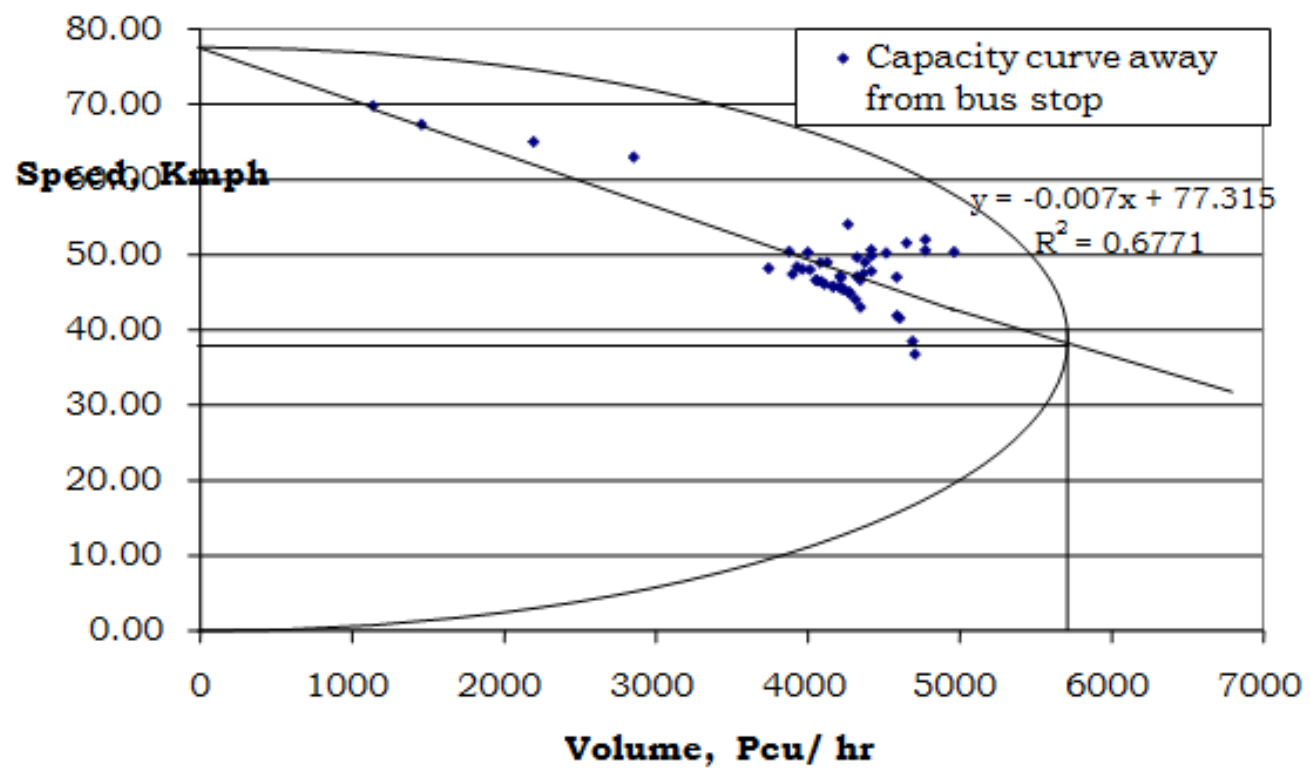

Fig 5. Bus Bhavan Bus Stop

$R W=9.4 \mathrm{~m} ; \mathrm{ERW}=$

$4.05 \mathrm{~m}$ 


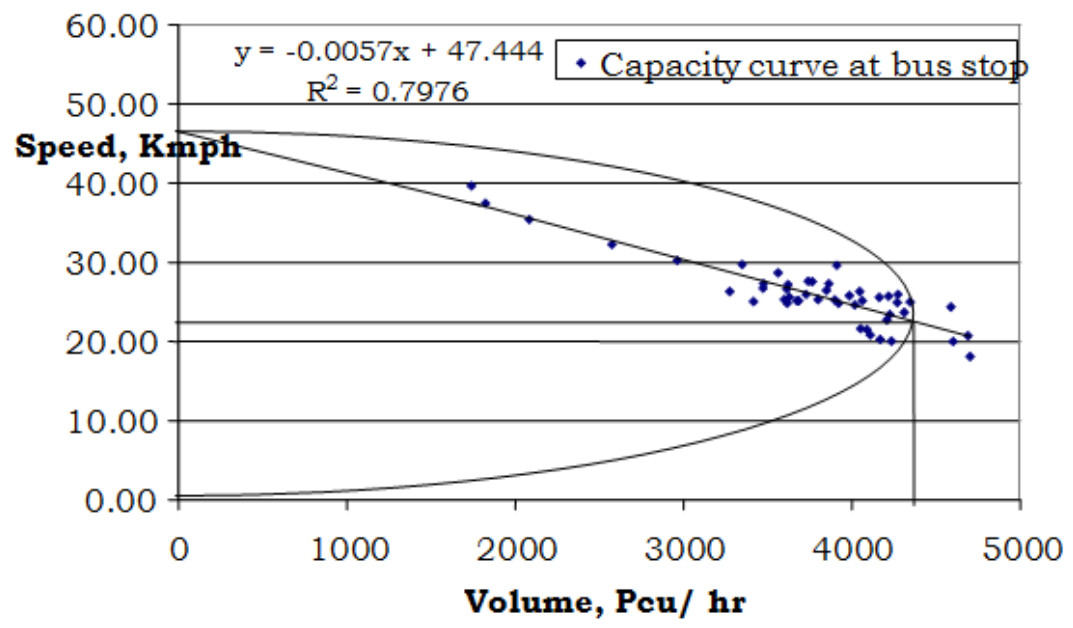

Fig 6. Bus Bhavan Bus stop RW=9.4 m; ERW=4.05 m

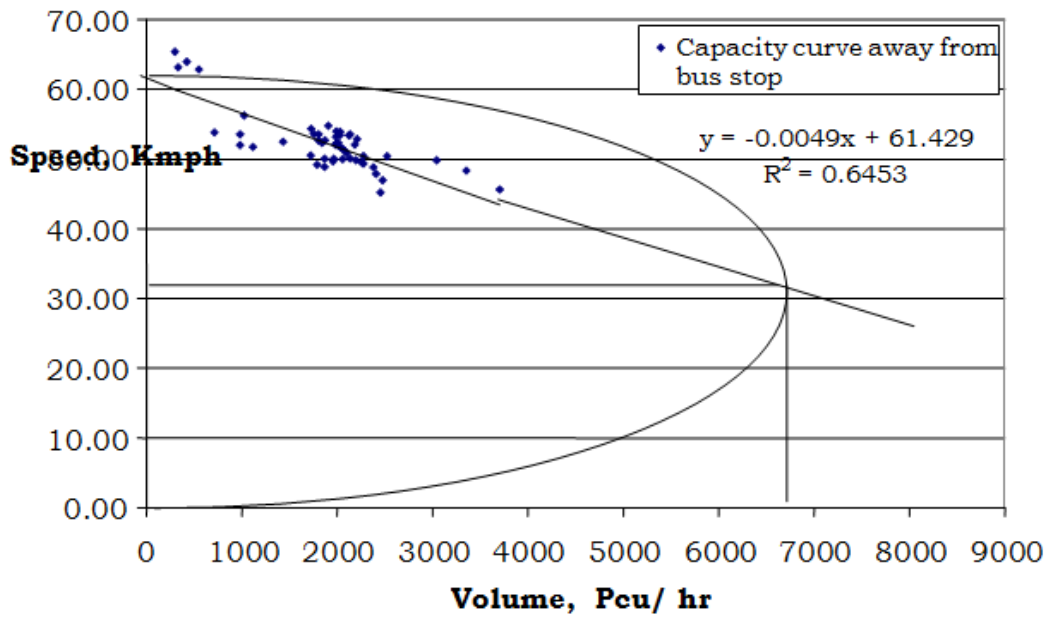

Fig 7. L I C Bus Stop $R W=12.2 \mathrm{~m} ; \mathrm{ERW}=6.98 \mathrm{~m}$

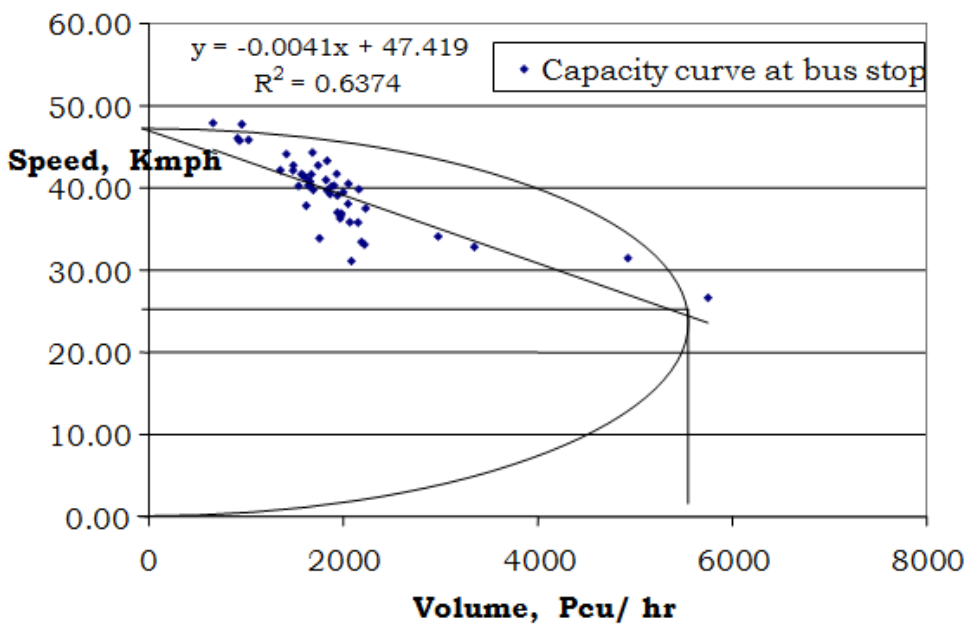

Fig 8. LIC Bus Stop RW=12.2 m; ERW=6.98 m

Similarly, the capacity curves plotted at Nalgonda X Roads bus stop are presented through Fig. 9 and Fig. 10. The approach capacity and Capacity values at this location are found to be $5475 \mathrm{pcu} / \mathrm{hr}$ and $3850 \mathrm{pcu} / \mathrm{hr}$ with a higher reduction in capacity of $1625 \mathrm{pcu} / \mathrm{hr}$. 


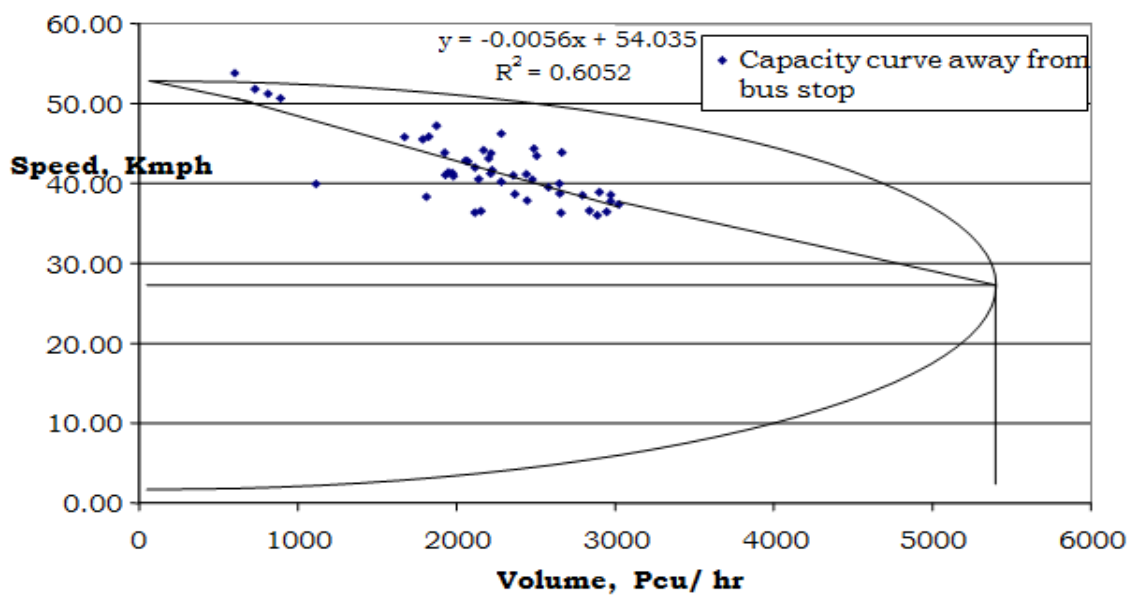

Fig 9. Nalgonda $\mathrm{X}$ Roads Bus Stop $\mathrm{RW}=8.2 \mathrm{~m}$; $\mathrm{ERW}=3.5 \mathrm{~m}$

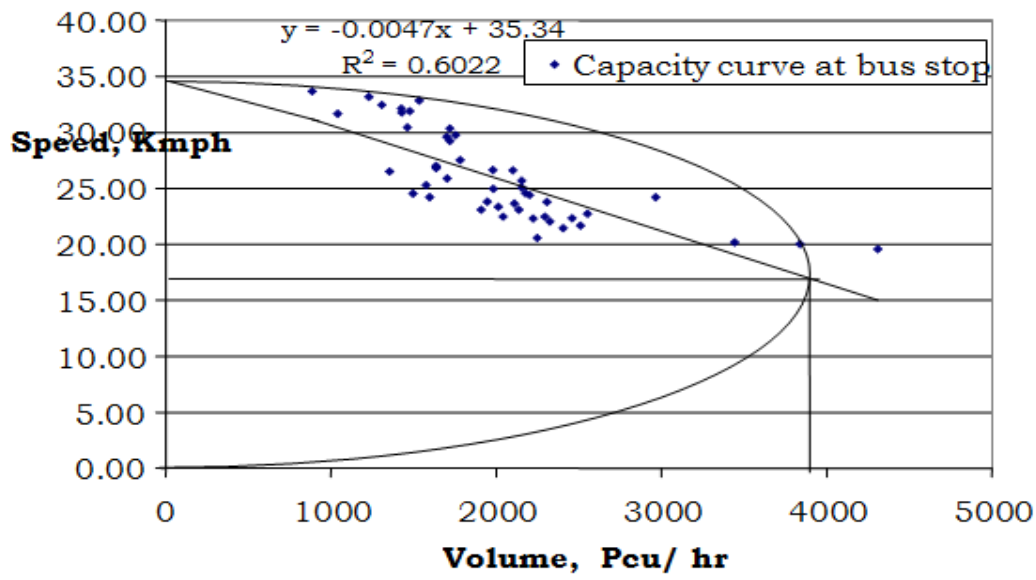

Fig 10. Nalgonda $X$ Roads Bus Stop $R W=8.2 \mathrm{~m}$; ERW=3.5 m

The estimated approach Capacity values and the Capacity values at bus stop with the reduction in Capacity values as obtained from the Capacity curves are presented through Table 2. From Table 2, it clearly indicates that the capacity at each section of the kerb side bus stop is reduced comparing to it's section capacity estimated away from each bus stop. The approach capacity estimated at all the bus stop locations is ranging from $5475 \mathrm{pcu} / \mathrm{hr}$ to $6750 \mathrm{pcu} / \mathrm{hr}$, where as the estimated capacity at bus stop at all the bus stop locations is ranging from $3850 \mathrm{pcu} / \mathrm{hr}$ to $5550 \mathrm{pcu} / \mathrm{hr}$. The estimated reduction in capacity of all sections is ranging between 1200 to $1625 \mathrm{pcu} / \mathrm{hr}$.

Table 2. Capacity Reduction - Location Wise

\begin{tabular}{|c|c|c|c|c|c|}
\hline $\begin{array}{c}\text { Name of the Bus Stop/ } \\
\text { Location }\end{array}$ & $\begin{array}{c}\text { Approach Road } \\
\text { Width, } \mathrm{m}\end{array}$ & $\begin{array}{c}\text { Approach } \\
\text { Capacity, Pcu/hr }\end{array}$ & $\begin{array}{c}\text { Average Effective Road } \\
\text { Width at Bus Stop, } \mathrm{m}\end{array}$ & $\begin{array}{c}\text { Capacity at bus } \\
\text { stop, Pcu/hr }\end{array}$ & $\begin{array}{c}\text { Reduction in Capacity at } \\
\text { Bus Stop, Pcu/hr }\end{array}$ \\
\hline Nalgonda X Roads & 8.2 & 5475 & 3.5 & 3850 & 1625 \\
\hline Bus Bhavan & 9.4 & 5800 & 4.05 & 4300 & 1500 \\
\hline LIC & 12.2 & 6750 & 6.98 & 5550 & 1200 \\
\hline
\end{tabular}

From the above capacity analysis at each kerb side bus stop, the reduction in capacity is considered to be higher at Nalgonda X Roads bus stop and is least at LIC bus stop. This is due to the reason that the impedance at Nalgonda X Roads bus stop is observed to be more and is least at LIC bus stop. So, it clearly indicates that the reduction in capacity is more at the location, where the speed reduction is more. The reduction in the speed at the kerb side bus stop is mainly due to the available effective road width. 


\section{Summery and Conclusions}

The evaluation of the speed of vehicles in a mixed traffic is a complex phenomenon which predominantly takes care of many influencing parameters that act either directly or indirectly on the traffic flow. The absence of lane discipline, the lack of road width due to encroachments by shop keepers, the presence of kerb side bus stops, uncontrolled side streets, street vendors, religious structures, the lack of enforcement measures, the lack of advanced technology, the lack of road space as per the vehicular growth and the lack of full fledged management techniques are some of the reasons for the congested traffic flow in urban areas. The capacity of road correspondingly reduces as the influence of the causal factors increase.

In the study, an attempt is made to quantify the reduction in capacity of the mid block due to the presence of kerb side bus stop. Three kerb side bus stops in Hyderabad city of variable road widths and traffic characteristics are considered. Traffic data such as traffic volume, speed and effective road widths are collected at and away from each bus stop for a period of 12 hours in a day covering both peak hours and non peak hours. The data is collected for every 15 minutes consecutive interval from 8 A.M. to 8 P.M. The width of the road at each of the bus stop is also measured. Capacity curves are then plotted at and away from each kerb side bus stop by considering the traffic volume and speed data and by using curve enveloping technique. The road capacity at and away from each bus stop is evaluated from the graphs and the reduction in capacity at each kerb side bus stop is then evaluated. It is observed from the estimated capacity values that the reduction in capacity at each section is not in accordance with the reduction in the road width alone, but it is due to the reduction in the Speed and effective road width at the respective bus stops which is found to vary based on various influencing parameters that are considered in the present study.

\section{References}

[1]. Anthony A. Saka, "Model for determining Optimum Bus- Stop Spacing in urban areas", Journal of Transportation Engineering @ ASCE, Vol 127, No. 3, May/June 2001, Page 195- 199.

[2]. David J. Victor and S. Moses Santhakumar, "Simulation Study of Bus Transit", Journal of Transportation Engineering, Vol. 112, No. 2, March 1986, Page 199- 211.

[3]. Gibreel G.M, Easa S.M and EI- Dimeery I.A, " Prediction of Operating Speed on Three dimensional Highway Alignments", Journal of Transportation Engineering, Vol 127, No. 1, January/February 2001, Page 21- 30.

[4]. Kay Fitzpatrick P.E, Shaw-Pin Miaou, Marcus Brewer P.E, Paul Carison P.E and Mark D. Wooldridge P.E, "Exploration of the Relationships between Operating Speed and Roadway features on Tangent Sections", Journal of Transportation Engineering @ ASCE, Vol 131, No. 4, April 2005, Page 261-269.

[5]. Key Fitzpatrick, William H. Schneider and Eun Sug Park, " Predicting Speeds in an Urban Right- Turn lane", Journal of Transportation Engineering @ ASCE, Vol 132, No.3, March 2006, Page 199- 204.

[6]. Kumar V.M \& Rao S.K, "Studies on Speed- Density - Flow Relationships on a few stretches of NH- 5 and NH- 6", Indian Highways, Vol 26, No. 12, December 1998, Page 33- 41.

[7]. Lakshmana Rao K.M, "Modelling for Development of Optimal Bus Stop locations using P- Median Method", Indian Highways, Vol 26, No. 8, August 1998, Page 29- 35.

[8]. Okutani, I and Stephanedes, Y.J, "Dynamic Prediction of traffic volume through Kalman filtering theory”, Transp. Res., Part B, Vol 18, No.1, 1984, Page 1- 11 .

[9]. Palanichamy M.S, Moses Santhakumar S, Thirumeninathan N \& Sivaganesan N, "User Perception of the Shuttle Bus Transit System of Madurai", Indian Highways, Vol 26, No. 6, July 1998, Page 25- 35.

[10]. Ranhee Jeong and Laurence Rilelf R, "Prediction Model of Bus Arrival Time foe Real Time Applications", Journal of Transportation Research Board, Vol 1927, 1981, Page 195-204.

[11]. Reebu Zachariah Koshy and V. Thamizh Arasan, "Influence of Bus Stops on flow characteristics of mixed traffic", Journal of Transportation Engineering @ ASCE, Vol 131, No. 8, August 2005, Page 640- 643.

[12]. Ruimin Li, Geoffrey Rose and Majid Sarvi, "Evaluation of Speed based travel time estimation models", Journal of Transportation Engineering @ ASCE, Vol. 132, No.7, July 2006, Page 540- 547.

[13]. Satish Chandra and Upendra Kumar, "Effect of Lane width on Capacity under mixed traffic conditions in India", Journal of Transportation Engineering @ ASCE, Vol 129, No.2, March/ April 2003, Page 155- 160.

[14]. Satish Chandra, "Effect of Road Roughness on Capacity of Two- Lane Roads", Journal of Transportation Engineering @ ASCE, Vol 130, No.3, May/ June 2004, Page 360- 364.

[15]. Shauna L. Hallmark, Keith K. Knapp and Christopher D. Grant, "Evaluating Speed differences between Cars, Light- duty trucks and Vans for Emissions Modeling”, Journal of Transportation Engineering @ ASCE, Vol 130, No.6, November/ December 2004, Page 814- 817 .

[16]. Thamizh Arasan V and Reebu Zachariah Koshy, "Methodology for Modeling Highway Heterogeneous traffic flow", Journal of Transportation Engineering @ ASCE, Vol 131, No. 7, July 2005, Page 544- 551.

[17]. Yogesh Dheenadayalu, Brian Wolshon and Chester Wilmot, "Analysis of Link Capacity Estimation Methods for urban planning Models”, Journal of Transportation Engineering @ ASCE, Vol 130, No. 5, September/ October 2004, Page 568- 575.

Dr Raju Ramesh Reddy. "Evaluation of Rate of the Reduction in Road Capacity at Kerb side Bus Stop in Urban areas under Mixed Traffic conditions - a case study in Hyderabad city." IOSR Journal of Mechanical and Civil Engineering (IOSR-JMCE) 14.4 (2017): 01-08. 